\title{
Construction and Application of Passenger Flow Simulation Evaluation Index System in Urban Rail Transit Transfer Stations
}

\author{
Xiaohong Fang ${ }^{1}$, Aijun Feng ${ }^{2}$ \\ ${ }^{1}$ Beijing Rail and Transit Design \& Research Institute CO., LTD, Beijing, China \\ ${ }^{2}$ Beijing Urban Construction Design \& Development Group CO., LTD, Beijing, China
}

\begin{abstract}
To popularize the efficient application of the passenger flow simulation technology in urban rail transit transfer stations, and make the simulation evaluation systematic, comprehensive and reasonable, a passenger flow simulation evaluation index system of transfer stations was constructed, based on the characteristics of transfer stations. Then the calculation method, evaluation scope and evaluation standard of each evaluation index were proposed. Finally, through Anhuaqiao station of Beijing urban rail transit, the evaluation index system and evaluation standards were verified feasible, comprehensive and effective.
\end{abstract}

\section{Introduction}

Transfer station of urban rail transit is the important place, whose efficiency affects the ability of the whole network and overall service level. At present, passenger flow simulation technology has gradually been used in the design and operation optimization of many urban rail transit stations, as a new technology to guarantee the construction and traffic organization scheme meet the demand of passenger flow distribution ability, and make sure the operation of the station safe and efficient. But it has not formed a set of complete evaluation index system, which causes differences in the selection of indicators of most applications due to the difference of cities, research units and the objects of study, makes it impossible to form example of the outcome, and also set up obstacles to pedestrian simulation technology application in a wider range. Therefore, the evaluation index system and evaluation standards of passenger traffic simulation in urban rail transit transfer stations, which could provide criterion for reasonable and effective evaluation of the transfer stations, is badly needed.

\section{Evaluation index system design principles}

Construction of a complete evaluation index system is complex system engineering, some principles must be considered:

- Systemic principle [1]: to reflect the status, characteristics and the dynamic change of evaluation objects from all aspects, to summarize each link of the whole object systematically and comprehensively, avoid one-sidedness.
- Objectivity principle: to ensure objectivity and impartiality of the evaluation index system, to ensure the comprehensiveness, reliability and accuracy of the data source.

- Scientific principle: the selection, definition, calculation method and measure of indicators must base on scientific theories, and could widely use in the service field of rail transit stations and the evaluation of pedestrian traffic facilities.

- Operability principle [1]: the indicators selected can be obtained by direct or indirect method, which have strong operability.

- Coordinative principle: the indicators in the meaning, calculation method and other various aspects should be coordinated with other related factors index system, which can avoid conceptual confusion.

\section{Hierarchical division of evaluation index system}

Traditional station hub designs mainly refer to code for metro design and other architectural design, and usually use static and average calculation method, which consider microcosmic behavior characteristics of pedestrian and emergency in the station inadequate, and unable to accurately judge the movement efficiency of passengers in stations [2]. Therefore, dynamic simulation evaluation must pay attention on "average" and "transient" at the same time, and also give consideration both to service level and emergency evacuation. Passenger flow simulation evaluation system in urban rail transit transfer stations was established by four types of indicators as capacity adaptation, instantaneous impact, comfort and emergency evacuation capacity, and then the types were subdivided into specific evaluation indicators. 
Hierarchical division of evaluation index system was shown in Fig. 1.

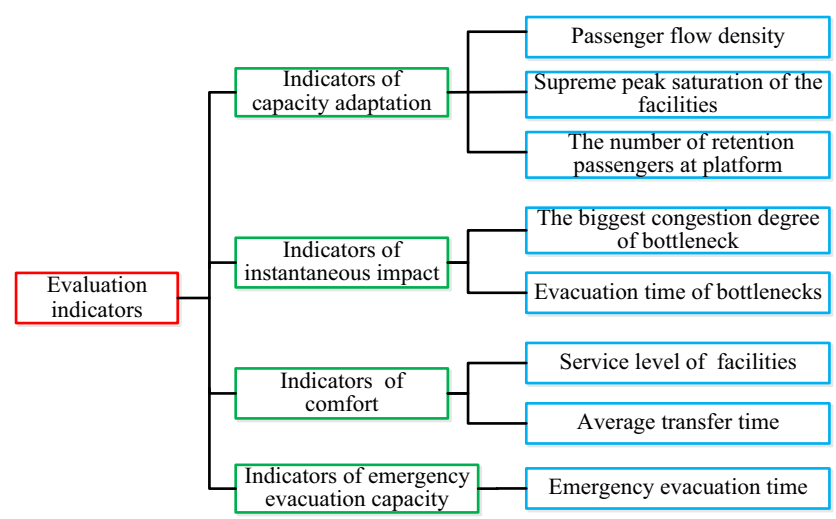

Figure 1. Hierarchical division of evaluation index system.

\section{Analysis of the evaluation indicators}

\subsection{Indicators of capacity adaptation}

\subsubsection{Passenger flow density}

The passenger flow density of urban rail transit refers to the number of people in each unit area. This indicator directly reflects the safety and comfort of the rail transit station area [3]. In the dynamic analysis, the traffic density is changing along with the passenger movements, which makes the value more in line with the actual operation state, including spatial and temporal distribution of the passenger flow density. Spatial distribution of the passenger flow density includes average passenger flow density distribution and instantaneous maximum passenger flow density distribution; the temporal distribution of the passenger flow density refers to the duration that various time points reach or exceed a certain density value (could be seen as the critical density) in station during the peak hours.

\subsubsection{Supreme peak saturation of the facilities}

The utilization efficiency ratio of the facilities reflects the level of coordination by the volume of passenger flows and the maximum capacity of traffic facilities. The ratio, denoted by $\theta$, can be expressed as a quotient of the throughput during supreme peak hours and the capacity of the facilities.

$$
\theta=\frac{Q_{h} * \rho}{C}
$$

In this equation, $Q_{h}$ represents throughput during peak hour; $C$ represents maximum capacity of traffic facilities; $\rho$ represent coefficient of supreme peak.

\subsubsection{The number of retention passengers at platform}

To insure the normal operations in transfer stations, all transfer demands should be satisfied, otherwise, passengers will be delayed and wait on the platforms. When the number of retention passengers at platform exceeds the capacity, the platform will get crowded and potential risks will appear. The accordance of the line capacity and the transfer passenger flow is represented by the number of the retention passengers on the platform. The retention passengers are rail transit riders who are waiting for the approaching train but fail to board the train because of crowd.

$$
M_{Z}=Q_{h}-C_{f} * \beta
$$

In the equation, $M_{Z}$ denotes number of retention passengers at the platform; $Q_{h}$ denotes number of people arriving at the platform; $C_{f}$ denotes available space of the arriving train compared to the capacity. $\beta$ denotes crowding coefficient (The value of crowding coefficient is related with the degree of the patience for passengers in subway cars).

\subsection{Indicators of instantaneous impact}

\subsubsection{The biggest congestion degree of bottleneck}

Passengers of rail transit arrive at stations with no continuity and equilibrium, but the traffic capacity of facilities is limited and fixed. Therefore, when large numbers of passengers reach a rail transit station within short a time, they may make a significant impact on facilities. This impact effect causes traffic congestion at different areas in the station. When too many passengers delay at one particular location, a bottleneck of traffic flow appears in the station. The bottleneck will affect other functions of the station and bring safety problems as well.

The bottlenecks often appear at stairs, escalators, ticket brakes, security checks and transfer channels. Sometimes, bottlenecks occur at waiting areas on the platform, passageways between stairs and the platform edges and queuing-up-for-checking areas outside of the station. The maximum congestion level of the bottleneck is reflected by the maximum number of assembling passengers or the maximum density of the bottleneck area in every passenger flow aggregation or evacuation process.

\subsubsection{Evacuation time at bottlenecks}

Because of the conflict between the dynamic passenger arrival rate and fixed transit capacity, when lots of passengers reach a rail transit station in a short time, the station becomes crowded. Moreover, the crowds cause bottlenecks of passengers' evacuation.

The evacuation time of a bottleneck is the time duration from when a bottleneck occurs to when the bottleneck disappears.

$$
T_{b}=T_{\text {start }}-T_{\text {stop }}
$$


In the equation, $T_{b}$ represents the evacuation time at a bottleneck; $T_{\text {start }}$ represents the time when a bottleneck appears and $T_{\text {stop }}$ represents the time when the bottleneck disappears.

\subsection{Indicators of comfort}

\subsubsection{Service level of facilities}

Service level is a comprehensive evaluation of passenger evacuation efficiency and walking comfort of different facilities. Indicators [2] of evaluating level of passenger service usually includes occupied area per passenger, maximum walking speed, freedom degree of pedestrians, the possibility of outpacing and crossing other passengers as well as the level of security and comfort. The service level of various facilities can be analysed and concluded automatically from the simulation software and the results are denoted by different colours. The performance of services is usually represented by cumulative time percentage within the simulating time. The output can be data table and diagrams.

\subsubsection{Average transfer time}

Transfer times refers to the time in a transfer station between a passenger getting off a train of a certain line and the passenger getting to another line he/she is about to get on. The average transfer time is the most intuitive indicator to reflect connection convenience. It typically includes walking time during transfer and waiting time during transfer. The transfer time a passenger spends to transfer in station $n$ can be expressed as follows.

$$
t_{n}^{h}=t_{n}^{b}+t_{n}^{W}
$$

In the equation, $t_{n}^{b}$ represents walking time during transfer and $t_{n}^{W}$ represents waiting time during transfer.

\subsection{Indicators of emergency evacuation}

Indicators of emergency evaluation are measured by the minimum evacuation time needed for all the people in the station to evacuate to safety regions in emergency. According to the current specifications, such as Code for Metro Design and Code for Design of Urban Rail Transit, emergency evacuation time usually refers to the minimum required time $[4,5]$ to evacuate all the persons (passengers on the incoming train, passengers and staff on the platform) from the train/platform to the station hall in peak hours.

The time to evacuate passengers in emergency circumstances can be calculated using the following equation.

$$
T_{e}=t_{a}+t_{r}+t_{m}
$$

In the equation, $T_{e}$ represents the total time needed for evacuation; $t_{a}$ represents the time needed for detecting emergencies; $t_{r}$ represents reaction time of passengers and $t_{m}$ represents the time of evacuating passengers.

\section{Evaluation scope and evaluation standard}

\subsection{Basic principles of evaluation standard}

1) If there are specific provisions in the relevant laws and regulations, standard, government documents of urban rail transit, the evaluation standard executes unified standard if the documents in accordance with the same standard, else executes the strictest standards if the file standard have conflicts.

2) Although there are no clear stipulations, but the evaluation criteria has be approved scientific and reasonable in the industry or through any form of expert review.

3) The evaluation criteria could reach the domestic and even international advanced level.

4) If there have not been any related standards, the evaluation criteria should be proved reasonable and reliable by qualitative or quantitative methods.

\section{2 Summary evaluation scope and evaluation standard}

The summary of simulation evaluation indicators and evaluation standards are shown in Table 1.

\section{Instance application}

\subsection{Station introduction}

Anhuaqiao station is the transfer station of Line8 with Line 12 in Beijing metro. The station of Line 12 is lay out east-west trending along the north third ring road, and the station of Line8 north-south trending along drum tower street [6].

The station of Line 12 is a three-floor underground island station, and the station of Line 8 is a two-floor underground island station. The two lines interchange passengers through transfer channels in Anhuaqiao station. Design scheme and Passenger flow organization scheme are shown in Figure 2 and Figure 3.

\subsection{Simulation test and scheme optimization}

According to the station planar construction scheme and passenger flow data prediction, the station passenger flow simulation model at morning peak hour is set up. Through simulation of the original station design model, it occurs serious congestion running to 7:25 am (morning peak hour 7:00-8:00), and the simulation is forced to stop.

In the original station design scheme, the facilities and transfer channel of Line12 can meet the demand of passenger flow in forward peak hour, but the number of transfer passengers between Line8 and Line 12 in 
forward peak hour is large, and streamline crossover before stars and escalators in south station hall of Line8 is serious. That cause serious congestion happened before two groups of stairs (escalators) of Line8, and make its capacity can't meet the traffic demand in forward peak hour.

Table 1. The summary table of simulation evaluation indicators and evaluation standard

\begin{tabular}{|c|c|c|c|c|c|c|}
\hline $\begin{array}{c}\text { Types of } \\
\text { evaluation }\end{array}$ & Evaluation Indicator & Implication & Evaluation scope & \multicolumn{2}{|c|}{ Evaluation standard } & $\begin{array}{c}\text { Evaluation } \\
\text { level }\end{array}$ \\
\hline \multirow{13}{*}{$\begin{array}{l}\text { Capacity } \\
\text { adaptation }\end{array}$} & \multirow{6}{*}{$\begin{array}{l}\text { Passenger flow density } \\
\quad\left(\text { person } / \mathrm{m}^{2}\right)\end{array}$} & \multirow{6}{*}{$\begin{array}{l}\text { Reflecting the traffic } \\
\text { congestion degree of } \\
\text { effective area(safety and } \\
\text { comfort of the area) }\end{array}$} & Side of the platform & \multicolumn{2}{|c|}{$1.33 \sim 3$ person $/ \mathrm{m}^{2}$} & - \\
\hline & & & $\begin{array}{l}\text { Middle walk area of } \\
\text { the platform }\end{array}$ & \multicolumn{2}{|c|}{$\leq 1.2$ person $/ \mathrm{m}^{2}$} & - \\
\hline & & & Station hall & \multicolumn{2}{|c|}{$\begin{array}{c}0.8 \text { person/ } \\
\mathrm{m}^{2}-1.0 \text { person/ } \\
\mathrm{m}^{2}\end{array}$} & - \\
\hline & & & \multirow{3}{*}{$\begin{array}{l}\text { Effective area of the } \\
\text { platform }\end{array}$} & \multicolumn{2}{|l|}{$<0.6$} & Good \\
\hline & & & & \multicolumn{2}{|l|}{$0.6 \sim 1.0$} & General \\
\hline & & & & \multicolumn{2}{|l|}{$>1.0$} & $\mathrm{Bad}$ \\
\hline & \multirow{3}{*}{$\begin{array}{l}\text { Supreme peak saturation } \\
\text { of the facilities }\end{array}$} & \multirow{3}{*}{$\begin{array}{l}\text { Reflecting the utilization of } \\
\text { facilities under the condition } \\
\text { of unbalanced time } \\
\text { distribution of passenger } \\
\text { flow }\end{array}$} & \multirow{3}{*}{$\begin{array}{l}\text { Security checks, ticket } \\
\text { brakes, stair, escalator, } \\
\text { channels, etc. }\end{array}$} & \multicolumn{2}{|l|}{$<0.8$} & Good \\
\hline & & & & \multicolumn{2}{|l|}{$0.8 \sim 1.0$} & General \\
\hline & & & & \multicolumn{2}{|l|}{$>1.0$} & $\mathrm{Bad}$ \\
\hline & \multirow{4}{*}{$\begin{array}{l}\text { The number of retention } \\
\text { passengers at platform } \\
\text { (person) }\end{array}$} & \multirow{4}{*}{$\begin{array}{l}\text { Reflecting the retention on } \\
\text { platform when a batch of } \\
\text { passenger flow come in } \\
\text { super hour }\end{array}$} & \multirow{4}{*}{$\begin{array}{l}\text { Upside and downside } \\
\text { platform }\end{array}$} & \multicolumn{2}{|l|}{$<0$} & Good \\
\hline & & & & \multicolumn{2}{|l|}{$0 \sim 292$} & General \\
\hline & & & & \multicolumn{2}{|l|}{$292 \sim 400$} & Not good \\
\hline & & & & \multicolumn{2}{|l|}{$>400$} & $\mathrm{Bad}$ \\
\hline \multirow{4}{*}{$\begin{array}{l}\text { Instantaneous } \\
\text { impact }\end{array}$} & \multirow{3}{*}{$\begin{array}{l}\text { The biggest congestion } \\
\text { degree of bottleneck }\end{array}$} & \multirow{3}{*}{$\begin{array}{l}\text { Instantaneous passenger flow } \\
\text { impact causes station } \\
\text { distribution bottleneck, } \\
\text { reflecting the congestion } \\
\text { degree of the } \\
\text { bottleneck(show as } \\
\text { congestion density) }\end{array}$} & Stair and escalator & \multicolumn{2}{|l|}{$<2.0$} & Acceptable \\
\hline & & & $\begin{array}{c}\text { Walk channel facilities, } \\
\text { such as transfer } \\
\text { channel, stair and } \\
\text { escalator } \\
\end{array}$ & \multicolumn{2}{|l|}{$<2.17$} & Acceptable \\
\hline & & & $\begin{array}{l}\text { Queue facilities, such } \\
\text { as the area before } \\
\text { stairs, tickets brakes, } \\
\text { security checks, } \\
\text { waiting zones }\end{array}$ & \multicolumn{2}{|l|}{$<3.33$} & Acceptable \\
\hline & $\begin{array}{l}\text { Evacuate time of } \\
\text { bottleneck(min) }\end{array}$ & $\begin{array}{c}\text { The duration from the } \\
\text { bottleneck appear to } \\
\text { disappear }\end{array}$ & Bottleneck facilities & \multicolumn{2}{|c|}{$\begin{array}{l}\text { Evacuated before the arrival } \\
\text { of next train }\end{array}$} & - \\
\hline \multirow{6}{*}{ Comfort } & \multirow{3}{*}{$\begin{array}{l}\text { Service level of } \\
\text { facilities[7] }\end{array}$} & & & Cumulative time & $\geq 70 \%$ & Good \\
\hline & & $\begin{array}{l}\text { Comprehensive evaluation of } \\
\text { the pedestrian evacuation } \\
\text { efficiency and comfort level } \\
\text { on facilities(shown as }\end{array}$ & $\begin{array}{l}\text { Platform, security } \\
\text { check, tickets brakes, } \\
\text { stair, escalator, }\end{array}$ & $\begin{array}{l}\text { proportion } \\
\text { achieves grade } \mathrm{C} \\
\text { and above in } \\
\text { queuing space and }\end{array}$ & $\begin{array}{l}50 \% \\
\sim 70 \% \\
\end{array}$ & General \\
\hline & & cumulative time proportion ) & channels, etc. & $\begin{array}{l}\text { grade } \mathrm{D} \text { and above } \\
\text { in walking space }\end{array}$ & $<50 \%$ & Not good \\
\hline & & Reflecting the impact of & & $<3$ & & Good \\
\hline & $\begin{array}{l}\text { Average transfer } \\
\text { time(min) }\end{array}$ & $\begin{array}{l}\text { transfer mode and facilities } \\
\text { perfect degree to transfer }\end{array}$ & All transfer directions & $3 \sim 5$ & & General \\
\hline & & time & & $>5$ & & $\mathrm{Bad}$ \\
\hline $\begin{array}{l}\text { Emergency } \\
\text { evacuation }\end{array}$ & $\begin{array}{l}\text { Emergency evacuation } \\
\text { time(min) }\end{array}$ & $\begin{array}{l}\text { Reflecting the least time for } \\
\text { passengers and staff to } \\
\text { evacuate to safe areas }\end{array}$ & $\begin{array}{l}\text { From platform to } \\
\text { station hall(or ground) }\end{array}$ & 6 & & - \\
\hline
\end{tabular}

Note:

1) Main standards come from "Code for Design of Metro", "Code for Design of Urban Rail Transit", "Construction Standards for Urban Rail Transit

Project", and "Fruin service level evaluation standard"; 2)The other standards were got from calculation and deduction based on the above reference.

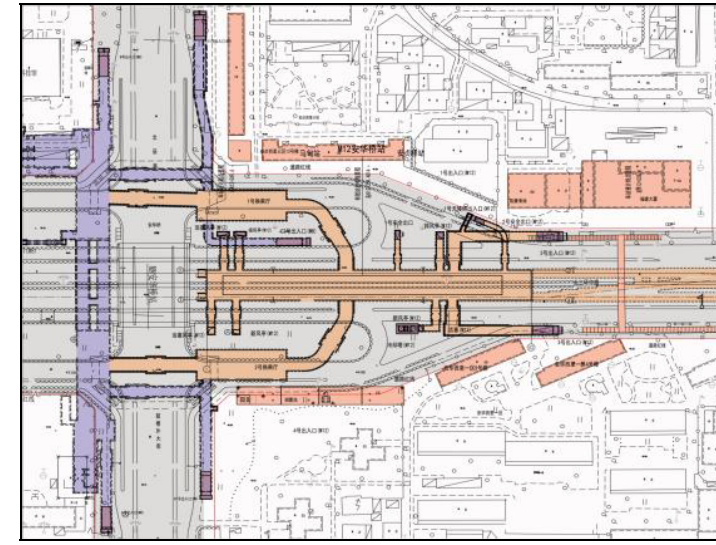

Figure 2. Design scheme of Anhuaqiao station.

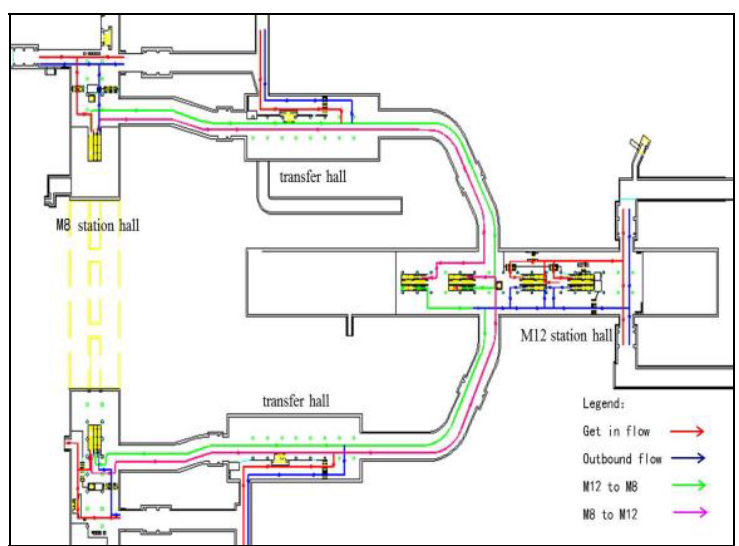

Figure 3. Passenger flow organization scheme of Anhuaqiao station. 
Therefore, the optimized station design increases two groups of ascending stairs and one-way transfer channel from Line 8 to Line 12 in the middle of the Line 8 station, change the original two-way transfer channel to one-way transfer channel from Line12 to Line8, and change the running direction of two escalators in the south of Line8, which can reduce streamline crossover, and alleviate the passenger flow pressure of the stairs (escalators) on both north and south sides of Line8. Through simulation of the optimized station design model, it can run smoothly from 7:00 am until 8:00 am. The congestion bottlenecks relieve obviously or disappear, and the station simulation operates in good condition.

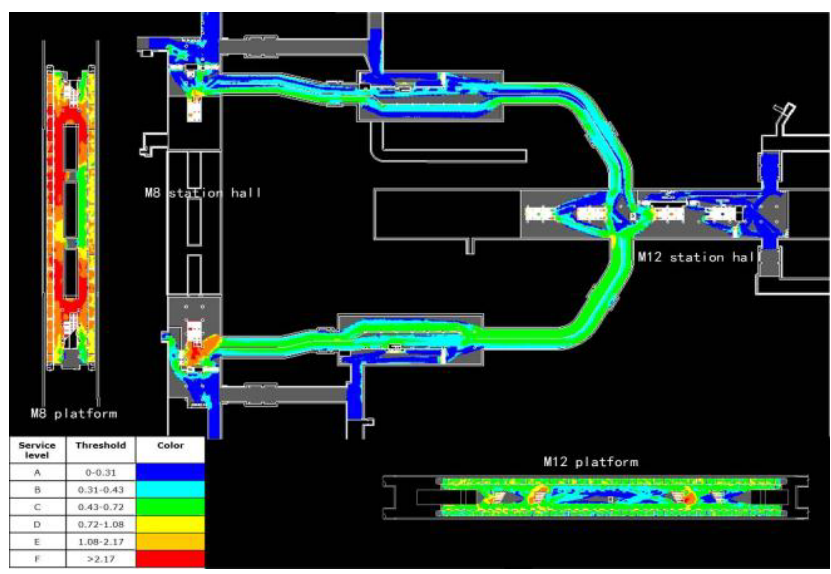

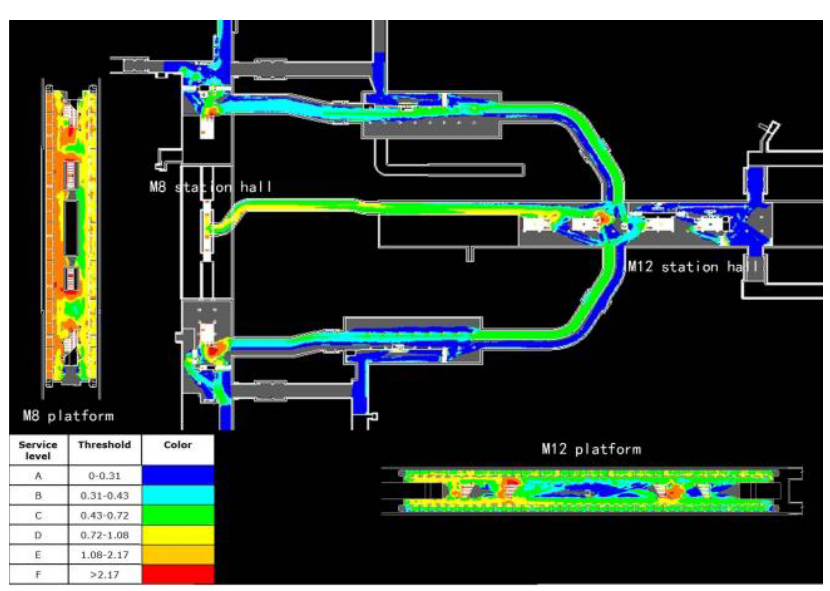

Figure 5. The average density figure of Anhuaqiao station optimal design scheme.

\subsection{Contrast of evaluation indicators}

According to the passenger flow simulation evaluation index system and evaluation standard proposed before, the instance chose some typical evaluation indicators, and make an effective assessment of the optimization effects through comparing the indicators before and after optimization.

Figure 4. The average density figure of Anhuaqiao station original design scheme.

\subsubsection{Passenger flow density of the side platform}

Table 2. Indicator contrast figure of passenger flow density of the side platform

\begin{tabular}{|c|c|c|c|c|}
\hline Test position & Applicable standard & $\begin{array}{c}\text { Test result of } \\
\text { original scheme }\end{array}$ & $\begin{array}{c}\text { Test result of } \\
\text { optimization scheme }\end{array}$ & Indicator contrast \\
\hline $\begin{array}{c}\text { The downside } \\
\text { platform of Line8 }\end{array}$ & $1.33 \sim 3$ person/ $\mathrm{m} 2$ & $\begin{array}{c}\text { Maximum } 3.10 \\
\text { person/ } \mathrm{m} 2\end{array}$ & $\begin{array}{c}\text { Passenger flow density of } \\
\text { the downside platform of } \\
\text { original scheme is bigger } \\
\text { than standard, but the } \\
\text { optimization scheme is in } \\
\text { the scope of the standard } \\
\text { value. }\end{array}$ \\
\hline
\end{tabular}

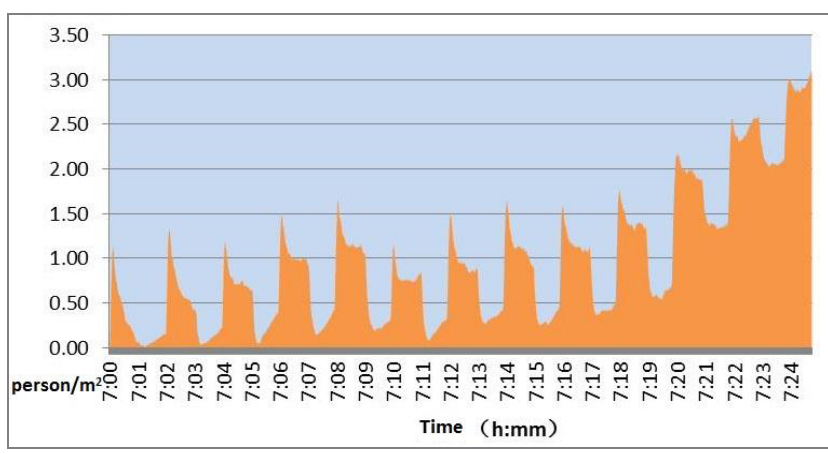

Figure 6. Passenger flow density statistics of Line 8 downside platform of original scheme.

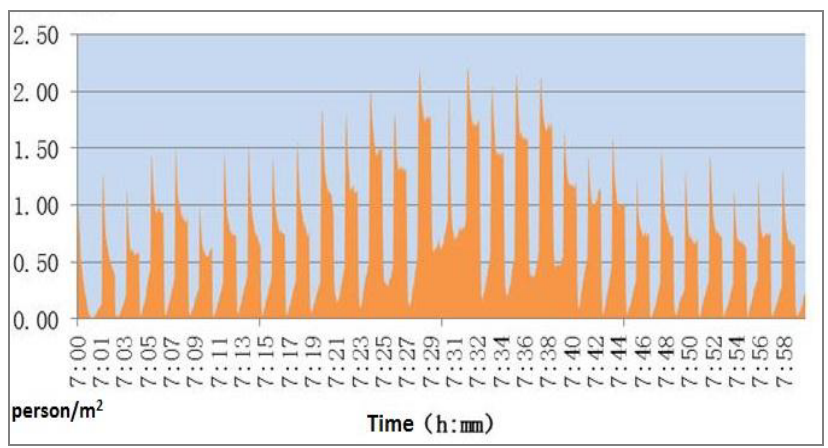

Figure 7. Passenger flow density statistics of Line 8 downside platform of optimization scheme. 


\subsubsection{Supreme peak saturation of the facilities}

Table 3. Indicator contrast figure of supreme peak saturation of the facilities

\begin{tabular}{|c|c|c|c|c|c|}
\hline Test position & \multicolumn{2}{|c|}{ Applicable standard } & $\begin{array}{l}\text { Test result of } \\
\text { orioinal scheme }\end{array}$ & $\begin{array}{l}\text { Test result of } \\
\text { optimization }\end{array}$ & Indicator contrast \\
\hline \multirow{3}{*}{$\begin{array}{c}\text { The south upward and } \\
\text { downward escalators } \\
\text { of Line } 8\end{array}$} & $<0.8$ & Good & \multirow{3}{*}{$\begin{array}{c}\text { Upward escalator: } \\
\text { saturation } 1.13 \text {; } \\
\text { Downward } \\
\text { escalator: } \\
\text { saturation0.99. }\end{array}$} & \multirow{3}{*}{$\begin{array}{c}\text { Upward } \\
\text { escalator: } \\
\text { saturation0.78; } \\
\text { Downward } \\
\text { escalator: } \\
\text { saturation0.75. }\end{array}$} & \multirow{3}{*}{$\begin{array}{l}\text { The capacity of upward and } \\
\text { downward escalators of original } \\
\text { scheme reaches saturation, so } \\
\text { adaptability is worse; but the } \\
\text { capacity of upward and downward } \\
\text { escalators of optimization scheme } \\
\text { is enough, so adaptability is good. }\end{array}$} \\
\hline & $\begin{array}{c}0.8 \sim \\
1.0\end{array}$ & General & & & \\
\hline & $>1.0$ & $\mathrm{Bad}$ & & & \\
\hline
\end{tabular}

\subsubsection{Facilities service level}

Table 4. Indicator contrast figure of facilities service level

\begin{tabular}{|c|c|c|c|c|c|c|}
\hline \multirow{2}{*}{ Test position } & \multicolumn{3}{|c|}{ Applicable standard } & $\begin{array}{c}\text { Test result of } \\
\text { original } \\
\text { scheme }\end{array}$ & $\begin{array}{c}\text { Test result of } \\
\text { optimization } \\
\text { scheme }\end{array}$ & Indicator contrast \\
$\begin{array}{c}\text { Queen area } \\
\text { before the south } \\
\text { stairs and } \\
\text { escalators of } \\
\text { Line8 platform }\end{array}$ & $\begin{array}{c}\text { Cumulative time } \\
\text { percentage achieves } \\
\text { grade C and above in } \\
\text { queuing space and } \\
\text { grade D and above in } \\
\text { walking space }\end{array}$ & $\begin{array}{c}20 \% \sim \\
70 \%\end{array}$ & General & $\begin{array}{c}\text { Cumulative } \\
\text { time percentage } \\
\text { achieved grade } \\
\text { C and above is } \\
6 \%\end{array}$ & $\begin{array}{c}\text { Cumulative time } \\
\text { percentage } \\
\text { achieved grade C } \\
\text { and above is } 71 \% \text {. }\end{array}$ & $\begin{array}{c}\text { Queen area service } \\
\text { level of } \\
\text { optimization } \\
\text { scheme improves } \\
\text { obviously } \\
\text { compared with the } \\
\text { original scheme. }\end{array}$ \\
\hline
\end{tabular}

\subsubsection{The biggest congestion degree of bottleneck}

Table 5. Indicator contrast figure of the biggest congestion degree of bottleneck

\begin{tabular}{|c|c|c|c|c|}
\hline Test position & $\begin{array}{c}\text { Applicable } \\
\text { standard }\end{array}$ & $\begin{array}{c}\text { Test result of original } \\
\text { scheme }\end{array}$ & $\begin{array}{c}\text { Test result of } \\
\text { optimization scheme }\end{array}$ & Indicator contrast \\
\hline $\begin{array}{c}\text { Queen area before } \\
\text { the south stairs and } \\
\text { escalators of Line8 } \\
\text { platform }\end{array}$ & $<3.33$ person/m2 & $\begin{array}{c}\text { Maximum } 4.16 \text { person/ } \\
\mathrm{m} 2\end{array}$ & $\begin{array}{c}\text { Maximum } 2.41 \text { person/ } / \\
\mathrm{m} 2\end{array}$ & $\begin{array}{c}\text { greater than the standard is } \\
\text { original scheme; but within the } \\
\text { scope of the standard value in } \\
\text { optimization scheme. }\end{array}$ \\
\hline
\end{tabular}

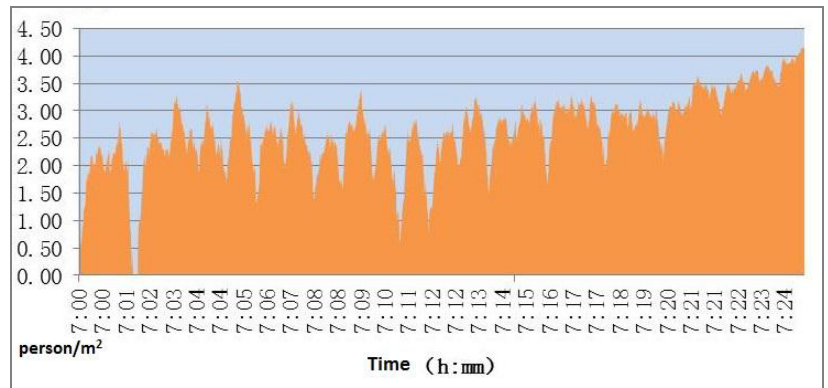

Figure 8. Queen area density statistics of south stairs on Line8 platform of original scheme

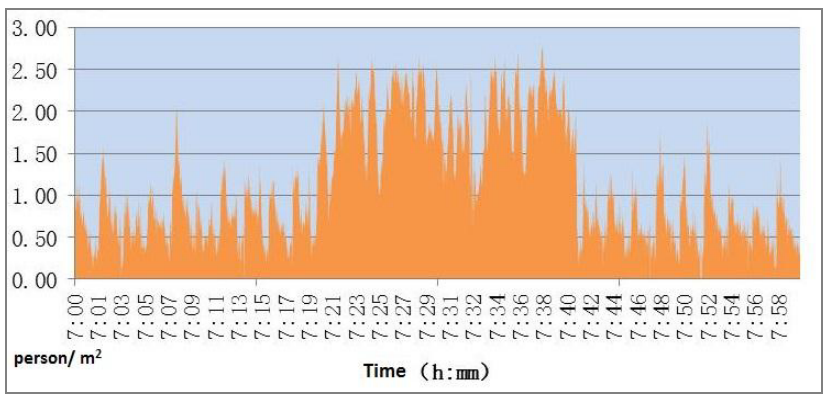

Figure 9. Queen area density statistics of south stairs on Line8 platform of optimization scheme

\subsubsection{Evacuate time of bottleneck}

Table 6. Indicator contrast figure of evacuate time of bottleneck

\begin{tabular}{|c|c|c|c|c|}
\hline Test position & Applicable standard & $\begin{array}{c}\text { Test result of original } \\
\text { scheme }\end{array}$ & $\begin{array}{c}\text { Test result of } \\
\text { optimization scheme }\end{array}$ & Indicator contrast \\
\hline $\begin{array}{c}\text { The platform of } \\
\text { Line8 }\end{array}$ & $\begin{array}{c}\text { Evacuate completely } \\
\text { before the arrival of } \\
\text { next train }\end{array}$ & $\begin{array}{c}\text { There are a large } \\
\text { number of passengers } \\
\text { stranded on the } \\
\text { platform }\end{array}$ & $\begin{array}{c}\text { There are a little } \\
\text { passengers stranded } \\
\text { on the platform }\end{array}$ & $\begin{array}{c}\text { Platform evacuate time is much } \\
\text { greater than departure interval } \\
\text { in original scheme, but less } \\
\text { than departure interval in } \\
\text { optimization scheme. }\end{array}$ \\
\hline
\end{tabular}




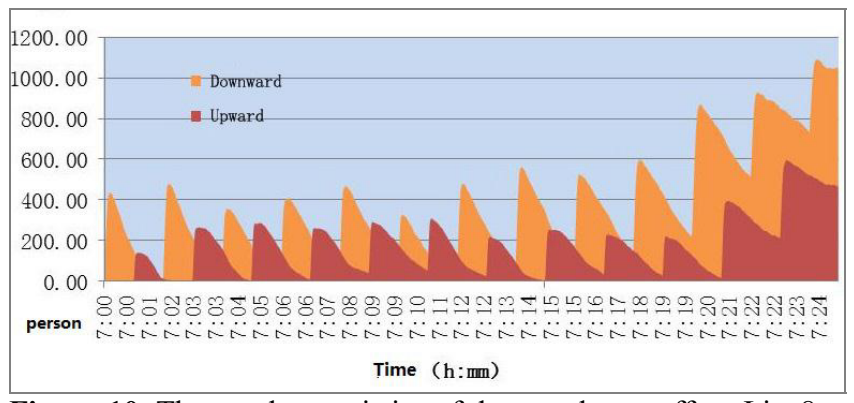

Figure 10. The number statistics of the people get off on Line8 platform of original scheme.

From the contrast of evaluation indicators, the optimized scheme is improved significant at passenger flow density, the degree of congestion, service level, and relief time of bottleneck compared with the original plan, and convenience and conform at transfer live up to the corresponding requirements. The instance verified the high feasibility, accuracy, efficiency and completeness of the passenger flow simulation evaluation index system and evaluation standards in urban rail transit stations proposed in this paper.

\section{Conclusion}

The evaluation index system covered four types of indicators of capacity adaptation, instantaneous impact, comfort and emergency evacuation capacity was proposed, based on multiple scientific applications of passenger traffic simulation in urban rail transit transfer stations. Then the evaluation index system was subdivided into eight specific indicators, such as passenger flow density, supreme peak saturation of the facilities, and service level of facilities and so on. These indicators reflected the possible problems of the transfer stations from different aspects. And the evaluation standard of each indicator was set. We hope that through more station simulation analysis, the evaluation index system and evaluation standard could be constantly revised perfect, and they can provide scientific decision support for the design and operation of transfer stations in urban rail transit.

\section{Acknowledgment}

This work is supported by Beijing Nova Program: Z141106001814027. And we thank the simulation project

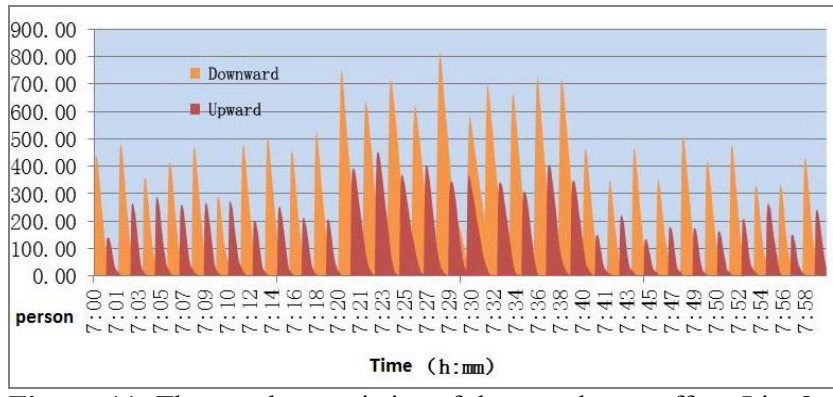

Figure 11. The number statistics of the people get off on Line8 platform of optimization scheme.

team of Beijing Rail and Transit Design \& Research Institute CO., LTD. for sharing the instance date of Anhuaqiao station.

\section{References}

1. Chu Dongzhu, Lin Yanyu, Wei Shuxiang. Application in Influenced Urban Realm Around Rail Transit Station Microscopic Pedestrian Simulation Method and Urban Design. Chongqing, Chongqing University Press, pp.58-59 (2015).

2. Li Dewei. Modeling and Simulation of Microscopic Pedestrian Flow in MTR Hubs. Beijing, Beijing Jiaotong University (2007).

3. Wu Yongyan, Liu Xiaoming, Wei Zhonghua, Rong Jian, Sun Lishan. "Simulation Evaluation on Pedestrian Facility Layouts of Transfer Station". Journal of Transport Information and Safety, vol. 30, pp. $74-77$ (2012).

4. GB 50157-2013 Code for Design of Metro. Beijing, China Planning Press (2013).

5. DB 11/995-2013 Code for Design of Urban Rail Transit. Beijing, Beijing Municipal Commission of Urban Planning and Beijing Municipal administration of Quality and Technology Supervision (2013).

6. Beijing Rail and Transit Design \& Research Institute CO., LTD. Research on Passenger Flow Simulation Technology in Urban Rail Transit and Construction of Evaluation Index System. Beijing (2014).

7. J. J. Fruin, "Pedestrian Planning and Design", Metropolitan Association of Urban Designers and Environmental Planners, New York, NY, USA (1971). 